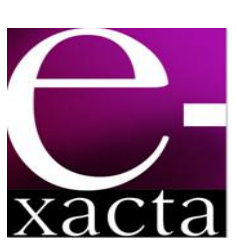

ISSN: 1984-3151

\section{AnÁlise do Desenvolvimento e Perspectivas MundiaIS dos BIOCOMBUSTíveIS DE PRIMEIRA E SEGUNDA GERAÇÃo}

\author{
Development Review and Prospects of the World's first \\ AND SECOND GENERATION BIOFUELS
}

\author{
Renata Carolina Zanetti Lofrano ${ }^{1}$; Lucas Augusto Ferreira de Oliveira ${ }^{2}$ \\ 1 Doutora em Ciências pela Faculdade de Filosofia Ciências e \\ Letras de Ribeirão Preto da Universidade de São Paulo \\ (FFCLRP/USP), 2002, e pós doutorado na área de \\ nanotecnologia pela FFCLRP/USP, 2004. Professora \\ Adjunto II do Departamento de Engenharia Química e \\ Estatística da Universidade Federal de São João Del Rei - \\ Campus Alto Paraopeba (DEQUE/UFSJ/CAP). \\ renataczlofrano@ufsj.edu.br. \\ 2 Graduando em Engenharia Química na Universidade \\ Federal de São João Del Rei - Campus Alto Paraopeba. \\ Rod. MG 443, km 7. Ouro Branco/MG. \\ lucas.aug.ferreira.oliveira@gmail.com.
}

Recebido em: 15/09/2015 - Aprovado em: 24/11/2015 - Disponibilizado em: 30/11/2015

\begin{abstract}
RESUMO: No mundo atual, com o rápido desenvolvimento econômico-industrial, a demanda por energia constantemente alta e as principais fontes usadas para a obtenção da mesma, são fontes findáveis. Cientes desse cenário, muitos países e governos desenvolveram políticas visando sua independência, total ou parcial, dos combustíveis fósseis. Uma alternativa viável são os biocombustíveis. Gerados por fontes renováveis, eles podem ser encarados, a primeira vista como fontes inesgotáveis de energia. Além disso, são menos prejudiciais ao meio ambiente, por liberarem menor quantidade de gases poluentes na atmosfera. Apesar disso, muito ainda pode ser feito para melhorar esse cenário energético. Pesquisas e desenvolvimento de novas tecnologias estão sendo feitas em todo o mundo. O presente trabalho visa à análise do status atual e previsões futuras para os biocombustíveis, considerando-se diferentes partes do mundo, as políticas adotadas e o potencial geográfico de produção desses biocombustíveis.
\end{abstract}

PalavRas-Chave: Biocombustíveis. Primeira geração. Perspectivas. Segunda geração.

ABSTRACT: In today's world, with the rapid economic and industrial development, the constantly high demand for energy and the main sources used to obtain the same are limited sources. Aware of this scenario, many countries and governments have developed policies to their independence, all or part of the fossil fuels. A viable alternative is biofuels. Generated by renewable sources, they can be seen at first glance as inexhaustible sources of energy. Furthermore, they are less harmful to the environment by releasing smaller amount of polluting gases into the atmosphere. Nevertheless, much can still be done to improve this energy scenario. Research and development of new technologies are being made worldwide. This study aims to analyze the current status and future forecasts for biofuels, considering different parts of the world, the policies adopted and the geographical potential production of these biofuels.

KEYWORDS: Biofuels. First generation. Perspectives. Second generation. 


\section{INTRODUÇÃo}

O desenvolvimento e a evolução de uma sociedade estão diretamente conectados às mudanças por ela sofridas. Essas mudanças só podem ser realizadas com energia e movimento. Desde o começo de sua existência, o ser humano vem criando e adaptando formas de conseguir com que essa evolução seja mais rápida e eficiente. A partir do século XIX, formas automáticas começaram a ser inseridas no cotidiano, sendo que a produção e criação de resultados passaram a crescer de forma exponencial. Entretanto, todo esse desenvolvimento traz consigo exigências: toda a gama de equipamentos atribuídos a esse rápido progresso necessita incessantemente de energia para promover seu funcionamento (CARRIQUIRY; TIMLSINA, 2010; SIMS; DUFEY; GRIEG, 2010; SIMS R.; TAYLOR M, 2008)

A forma encontrada para suprir essa grande demanda energética está depositada a centenas de metros abaixo da terra, no petróleo. Grandes moléculas de hidrocarbonetos pesados, que quando quebrados, trazem uma fonte de energia enorme. Durante décadas, se pensou que o problema envolvendo fontes de energia para os instrumentos criados, na era industrial, estava resolvido. Todavia, observaram-se algumas variáveis, que trouxeram à tona a extenuação dessa fonte (DUFEY; GRIEG, 2010; SIMS; TAYLOR, 2008).

O petróleo é uma fonte de energia não renovável. Isso implica que em algum momento, ele deixará de existir. Para o ser humano, se tornar cada vez mais dependente de uma fonte energética assim, vai contra o fluxo natural de sua evolução. Outra vertente que começou a ser analisada nos últimos anos são as consequências que o petróleo traz ao ambiente. Ao ser quebrado por meio de queima, a grande molécula de hidrocarboneto do petróleo é transformada em hidrocarbonetos menores, que são liberados, em sua grande maioria no estado gasoso, para a atmosfera.
No curto prazo, os efeitos provocados não são significativos. Mas analisando-se os resultados provenientes, das últimas décadas de liberação ininterrupta de gases na atmosfera, pode-se perceber um elevado dano promovido ao meio ambiente (CARRIQUIRY; TIMLSINA, 2010; SIMS; DUFEY; GRIEG, 2010; SIMS R.; TAYLOR M, 2008).

Sabendo-se que o petróleo, principal fonte de energia do mundo é esgotável, muitos países começaram a buscar fontes que pudessem ser consideradas, fontes ilimitadas de energia (CARRIQUIRY; TIMLSINA, 2010; SIMS; DUFEY; GRIEG, 2010; SIMS R.; TAYLOR M, 2008).

Como resultado, encontrou-se uma fonte, que à primeira vista, para muitos, não apresentava desvantagens, o biocombustível. Em definição direta, o biocombustível é um combustível que contém energia obtida a partir de fontes que tiveram fixação de carbono recente. Pode-se citar o caso da produção de álcool (obtido a partir de fontes vegetais com alta concentração de açúcar, como a cana de açúcar, o milho ou a beterraba) que foi considerada por muito tempo a solução para o problema em questão, pois sua queima, além de poluir menos a atmosfera, era considerada uma fonte ilimitada de energia (SCHOOT, 2009).

O biodiesel é produzido em mais de trinta países no mundo, sendo que 21 deles já utilizam o combustível e 11 países estão implantando seus programas. Os atores mais importantes, em certa medida, coincidem com os produtores de álcool. Mas é sempre necessário destacar que, ao contrário do álcool, o biodiesel não pode prescindir de combustíveis fósseis (TAVORA, 2012).

Mas novamente, após alguns anos, algumas variáveis antes não consideradas relevantes para o processo, foram se mostrando importantes. O problema de o petróleo ser uma fonte finita poderia sim ser 
sobreposto à criação de energia proveniente do álcool. Entretanto, essa solução traz consigo uma questão implícita. Questão que envolve fatores mais complexos. De forma geral, esse problema se resume ao fato, que a cana de açúcar, o milho e a beterraba, que antes eram usadas como fontes de alimento humano agora estavam sendo utilizadas para a produção de combustíveis. Dessa forma, pessoas teriam que deixar de se alimentar em detrimento do suprimento energético das máquinas (GAROFALO, 2013; SCHOOT, 2009).

Além dessa questão, empresários do mundo inteiro, ligados a empresas petrolíferas se mostravam insatisfeitos com a ideia de ter sua fonte de recursos financeiros sendo descartada da noite para o dia. Medidas políticas foram tomadas para frear a produção do álcool (GAROFALO, 2013).

Analisando o escopo geral, a produção energética atual, envolve fatores ambientais e geográficos, por considerar lugares onde existem fontes de petróleo ou plantações de cana de açúcar podem ser cultivadas. E fatores econômicos, pois é irrelevante o uso de uma fonte de energia que tem seu custo maior do que o do produto gerado, pela máquina ou processo alimentado por essa energia. E por último, envolve também fatores sociais e políticos, que levantam questões que são amplamente discutidas mundialmente, apresentando diferentes soluções para cada região. Essa consideração geográfica deve ser considerada quando uma análise energética é feita. A seguir, uma análise energética é realizada considerando-se as cinco diferentes regiões no mundo: América do Norte, América do Sul, África, Europa e Ásia.

\section{ANÁLISE E DESENVOLVIMENTO POR REGIÕES}

Em se tratando de matrizes energéticas, existem diversas formas e posturas de se abordá-las, perante o que se considerar prioritário ou superficial. Existem distintas culturas e formas de pensar, gerando assim, decisões diversificadas (GAROFALO, 2013; SCHOO, 2009).

Além da diferença cultural entre os povos, deve-se considerar também a situação atual de cada povo. Em alguns casos, existem ideias consideradas boas, mas que por hora, não podem ser implementadas, devido ao elevado custo de certa tecnologia existente ou por falta de recursos geográficos. Devido a isso, a análise energética proposta nesse artigo, será feita por regiões, sendo elas subdivididas, como já citadas antes, em América do Norte, América do Sul, África, Europa e Ásia (GAROFALO, 2013; SCHOOT, 2009).

\subsection{AMÉRICA DO SUL}

\subsubsection{Fatores Ambientals e Geográficos}

Em se tratando de fatores ambientais e geográficos, a América do Sul pode muito provavelmente, ser considerada a melhor das regiões analisadas dentre todas, no estudo apresentado neste artigo (DIOP; BLANCO, 2013).

Conhecida como forte produtora de produtos primários, a América do Sul já produzia, em grande escala, a maioria dos produtos usados para o desenvolvimento de biocombustíveis, pois estes eram plantados em sua maioria, para fins alimentícios. Esse é um dos motivos para que atualmente, junto com a América do Norte, quase $85 \%$ da produção de biocombustíveis esteja ligada a estas duas grandes áreas (LUCON, 2008).

A América do Sul quase não contribui para a presença de poluentes na atmosfera. Isso fica claro, tomando-se como exemplo a matriz energética brasileira em 2014 (FIG. 1), na qual se observa que de todas as fontes energéticas brasileiras a biomassa corresponde a $7 \%$ de toda energia produzida, ocupando assim a terceira posição em relação às demais fontes (DIOP; BLANCO, 2013, GADONNEIX, 2010; LUCON, 2008). 


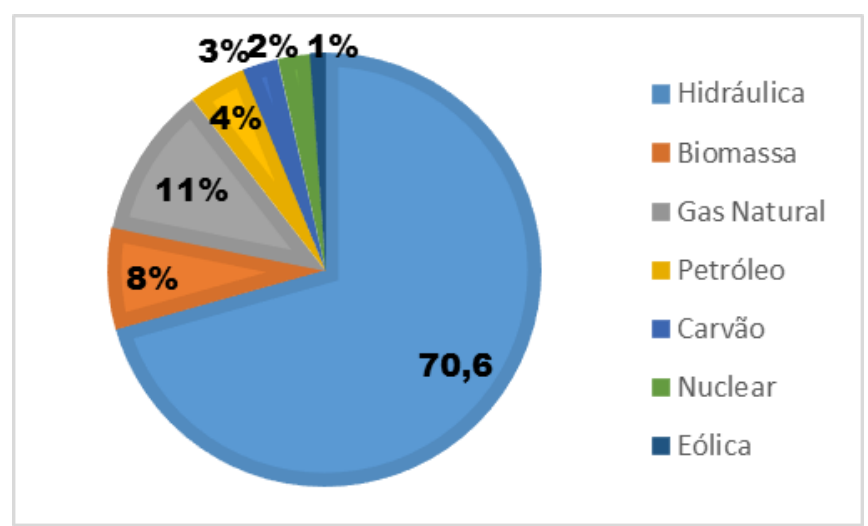

Figura 1 - Matriz Energética do Brasil em 2014. Fonte - MARTIN, 2014.

$\mathrm{Na}$ América do Sul principalmente, os temas biocombustíveis de primeira e segunda geração são muito discutidos. Os biocombustíveis de primeira geração são aqueles gerados diretamente de fontes provenientes da terra, como o milho, a cana de açúcar, beterraba e que necessariamente, são usadas para consumo humano. Os de segunda geração são aqueles gerados por diversas fontes da biomassa (geralmente compostos celulósicos), não usadas na alimentação humana (DIOP; BLANCO, 2013, GADONNEIX, 2010; LUCON, 2008).

Essa discussão é focada no uso de fontes alimentícias para a produção de biocombustíveis de primeira geração, no mundo onde tantas pessoas estão em condições alimentícias precárias. Estudos mostram que em algumas regiões, consideradas de extrema pobreza a produção de biocombustíveis já influencia a produção de alimentos para a população (DIOP; BLANCO, 2013; MAURON, 2014).

\subsubsection{FATORES ECONÔMICOS}

A produção de combustíveis a partir de fontes renováveis é na teoria, uma excelente ideia. Entretanto, se faz necessário considerar variáveis que não são levadas em conta à primeira instância (GADONNEIX, 2010).
A produção de combustíveis provenientes de fontes fósseis nos dias de hoje, é realizada em escala extraordinária. O estudo e pesquisa de como se produzir, em melhores condições de preparo e produção, as otimizações de cada etapa, já foram atingidas. Em contrapartida, os biocombustíveis são uma fonte energética relativamente nova. Sua pesquisa e desenvolvimento ainda estão sendo desenvolvidas e ainda existe muito a evoluir. Sua produção não é feita ainda em larga escala, como a dos combustíveis fósseis e seu processo produtivo apresenta rendimentos não satisfatórios, que precisam ser melhorados (MAURON, 2014).

Por esses motivos, os custos da produção dos biocombustíveis se tornam elevados, e uma premissa básica existente no mundo atual é a que se existem dois métodos para se obter 0 mesmo produto, 0 processo com menor custo é sempre o melhor. Por isso, nos dias de hoje, economicamente falando, ainda é mais vantajoso a produção de combustíveis fósseis em relação à de biocombustíveis (GADONNEIX, 2010).

Incentivos fiscais feitos corretamente, apoio governamental e industrial, podem reverter esse quadro. Pois, sendo limitados, os combustíveis fósseis tendem a se tornar cada vez mais caros (GADONNEIX, 2010).

\subsubsection{Fatores PoLÍticos}

Existem diversos pontos que desaceleram a produção de biocombustíveis sob o aspecto político. O ramo de óleo e gás, além de ser extremamente forte na atualidade, tem grande poder nas decisões tomadas pelos países. O fluxo de recursos financeiros existente, a criação direta e indireta de empregos, o desenvolvimento geográfico onde as indústrias são instaladas. Todos estes fatores juntos demonstram a 
grande influência das empresas que atuam nessa área, na gestão de um país (GADONNEIX, 2010).

Ao considerar a mudança de fontes energéticas, um governo deve ponderar que esta alteração acarretará consequências para o Estado e para a população. Ao incentivar o ramo de biocombustíveis, as empresas de óleo e gás perdem investimentos, consumidores e lucros. Isso gera em primeira análise, uma queda de fluxo monetário e um aumento no desemprego (GADONNEIX, 2010).

Uma decisão governamental sensata conjugaria 0 desenvolvimento do crescimento da produção e consumo dos biocombustíveis gradativamente e paralelamente com a manutenção dos combustíveis fósseis. Basicamente, é isso que têm sido feitos pelos governos da América do Sul nos dias atuais (DIOP; BLANCO, 2013).

Na Colômbia, por exemplo, vigorava desde 2005, uma lei que define a adição de no mínimo $10 \%$ de etanol na gasolina vendida em cidades com população acima de 500.000 pessoas. Desde 2009, esta lei vigora em todas as cidades e está em execução até os dias de hoje. Na Venezuela, as empresas de óleo e gás apoiaram e investiram na construção de 15 destilarias de cana de açúcar desde 2006, além de o governo venezuelano ter apoiado a introdução da lei E10, que também introduz $10 \%$ de etanol na gasolina vendida. Em 2012, o fator de etanol na gasolina dobrou para 20\% (ECONOMIST, 2011; NOLTE, 2012).

O governo brasileiro lançou na década de 1970 o programa Proálcool, que incentivava a compra de automóveis movidos a álcool, tentando assim, diminuir a dependência ao petróleo e incentivar o plantio de cana-de-açúcar. Com a criação desse programa, vários outros foram criados na tentativa de amenizar essa dependência. Programas pós-Proálcool visavam expandir a produção de biodiesel que deveria diminuir gradativamente, a dependência energética no álcool.
A partir de 2005, o Brasil começou a desenvolver uma produção consistente de biodiesel para atendimento aos limites a serem adicionados ao diesel em conformidade com a legislação brasileira, 2-3\% em 2008, 4\% em 2009, 5\% em 2010 e chegando a 7\% em 2014. (ECONOMIST, 2011; SOARES, 2014)

\subsection{AMÉRICA dO NORTE}

\subsubsection{Fatores Políticos}

A Lei político-energética americana foi aprovada pelo Congresso dos Estados Unidos em julho de 2005 e assinada pelo presidente George W. Bush em agosto de 2005. A lei, descrita pelos defensores como uma tentativa de combater os crescentes problemas de energia, mudou a política energética dos Estados Unidos, através de incentivos fiscais e garantias de empréstimos para a produção de energia de vários tipos. Em 2006, George W. Bush disse em um discurso do Estado da União que os EUA estão "viciados em petróleo" e deveriam substituir $75 \%$ do petróleo importado até 2025 por fontes alternativas de energia, incluindo biocombustíveis (ECONOMIST, 2011).

Essencialmente todo o combustível de etanol nos EUA é produzido a partir do milho. Esta é uma fonte cuja produção envolve alto consumo de energia, uma unidade de energia de combustível fóssil para criar apenas 0,9-1,3 unidades de energia de etanol. A legislação americana obriga 0 uso mínimo do combustível E10 (gasolina com 10\% de etanol) até 2012 em todos os carros nos EUA. Em 2014, esta porcentagem passou a ser de 20\% (APEX, 2014; SIMS R.; TAYLOR M, 2008; SOARES, 2013).

A lei americana de Segurança Energética de 2007 exige que a população americana consumidora de combustíveis deva usar pelo menos 36 bilhões de galões norte-americanos (140 milhões de $\mathrm{m}^{3}$ ) de biocombustíveis em 2022. Este é um aumento de 
quase cinco vezes em relação aos níveis atuais. Isso está causando uma mudança significativa na disponibilidade de matéria-prima para a produção de alimentos. As exportações de alimentos norteamericanos diminuíram (aumentando os preços dos grãos em todo o mundo), e as importações de alimentos pelos EUA aumentaram significativamente. A partir de 2013 as exportações começaram a crescer gradativamente e os preços se mantiveram estáveis (APEX, 2014; SIMS R.; TAYLOR M, 2008; SOARES, 2013).

Hoje a maioria dos biocombustíveis nos Estados Unidos não é rentável sem subsídios significativos, mesmo assim, os Estados Unidos continuam entre os maiores produtores de biocombustíveis do mundo. $\mathrm{O}$ Programa de etanol dos Estados Unidos é resultado de subsídios governamentais. Nesse Programa existem mais de 200 tipos diferentes de subsídios (SOARES, 2013;'ECONOMIST, 2011).

Grandes empresas americanas pretendem produzir combustível E85 (85\% da composição baseada em etanol) a partir de etanol de celulose. O único fator que faz com que esse projeto não seja executado em larga escala é que o lucro de produção ainda não é satisfatório para esse tipo de execução. Existe ainda uma pesquisa sobre qual a matéria-prima ideal para esse tipo de combustível. A General Motors, por exemplo, já possui carros E85 sendo produzidos. Mas a produção atual de etanol dos Estados Unidos ainda é baixa para suprir a demanda direcionada ao uso de automóveis E85 em grande escala e com isso, várias empresas estão aumentando sua produção de etanol atualmente. A tendência é que o processo de produção seja cada vez mais eficiente, gastando menos. Com isso, as emissões de gases de efeito estufa serão reduzidas consideravelmente com o uso exclusivo de biocombustíveis à base de celulose e milho (APEX, 2014; ECONOMIST, 2011).
Em 2008, o governo americano tomou uma medida legislativa na qual investia 288 milhões em subsídios agrícolas dos Estados Unidos, bem como buscaria áreas energéticas, de conservação, nutrição e desenvolvimento rural. Algumas iniciativas específicas no projeto de lei incluem aumentos nos benefícios do vale-refeição para os trabalhadores da área rural, aumento do apoio à produção de etanol celulósico, e recursos para a pesquisa de pragas, doenças e outros problemas agrícolas (ECONOMIST, 2011).

O Canadá segue os passos dos Estados Unidos. O governo canadense deliberou que a partir de 2010, pelo menos $45 \%$ do consumo de gasolina do país seria composta de gasolina, com no mínimo 10\% de álcool na sua composição. Promovendo assim, a gradativa inserção de álcool no seu mercado de combustíveis. Diminui também os impostos para agricultores que plantam matéria-prima para a produção dos biocombustíveis. (ECONOMIST, 2011)

\subsubsection{Fatores Ambientais e GeOgrÁficos}

A América do Norte não tem uma vasta gama de opções de culturas voltadas à produção de biocombustíveis, como a América do Sul. Para a produção de biocombustíveis, o milho é a matéria prima principal usada, mesmo não sendo a fonte mais viável se comparada às demais em nenhum aspecto relevante. $\mathrm{O}$ milho tem uma eficiência energética baixa e gera mais gases poluentes se comparado com outras fontes tradicionais (FIG. 2). (SOARES, 2013).

A principal preocupação dos Estados Unidos e Canadá encontra-se no setor econômico. O petróleo é uma fonte finita e tende a ficar cada vez mais caro. Uma alternativa é driblar essa dependência do petróleo. O milho é a fonte mais barata para estes países, o que justifica seu uso em grande escala (SOARES, 2013). 


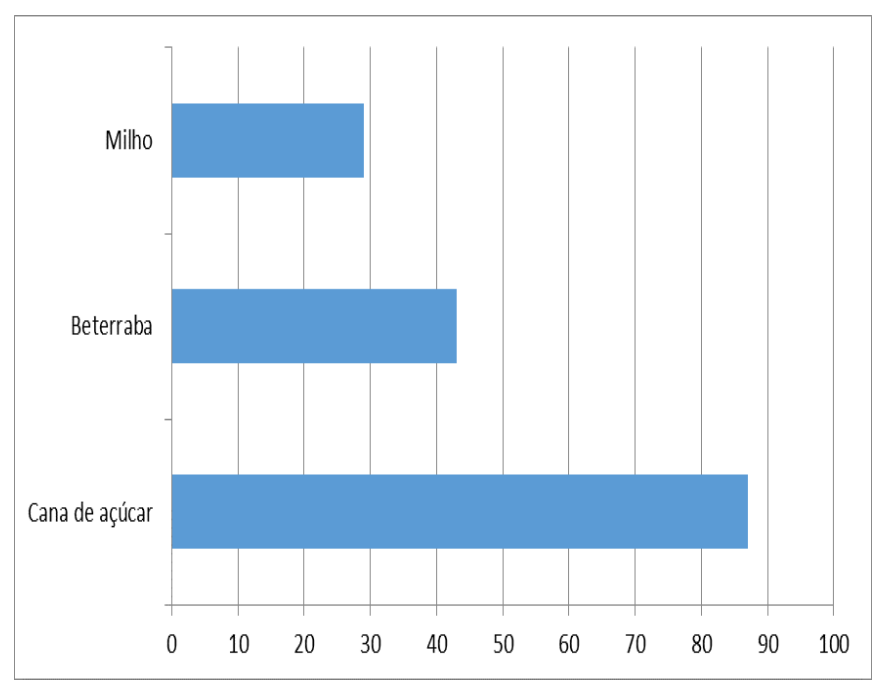

Figura 2 - Redução de gases poluentes em relação à gasolina (\%)

Fonte - SIMS R.; TAYLOR M, p. 1.

\subsubsection{FATORES ECONÔMICOS}

A América do Norte investe alto no desenvolvimento dos biocombustíveis. Esse investimento visa à diminuição da dependência pelos combustíveis fósseis. Só no ano de 2013, os Estados Unidos gastaram cerca de 30 bilhões de dólares nesse setor. O objetivo há longo prazo, visa principalmente o lucro do país com esses biocombustíveis, pois em algumas décadas os EUA serão provavelmente o país mais desenvolvido nessa área (ECONOMIST, 2011).

\section{3 ÁfricA}

\subsubsection{Fatores Políticos}

"A África está muito atrás do resto do mundo quando se trata de biocombustíveis". Essa frase foi dita pelo ministro de energia da África do Sul em 2008. Os motivos que o levaram a esse comentário podem ser justificados pelo fato da África estar altamente ligada aos maiores produtores de petróleo bruto no mundo. Apesar de possuir um vasto potencial de desenvolvimento, pesquisa e cultivo de matéria primas para a produção de biocombustíveis, o país segue uma política de não melhorias na infraestrutura atual e negligencia qualquer apoio às novas tecnologias. $O$ atual governo preza pela manutenção das fontes energéticas já implementadas no país (COYLE, 2012; GAROFALO, 2005).

\subsubsection{Fatores Ambientais e Geográficos}

A África possui um enorme potencial quando se trata do desenvolvimento de matérias primas para a produção de biocombustíveis (COYLE, 2012; GAROFALO, 2005).

Com um clima e tipo de terreno amplo, parecido com o que o Brasil apresenta a África, com os investimentos e políticas adequadas, possui potencial para produzir em larga escala, biocombustíveis de diferentes tipos, para áreas diversas (COYLE, 2012; GAROFALO, 2005).

Atualmente a África do Sul investe principalmente no plantio de culturas voltadas para a produção de biocombustíveis, principalmente biodiesel, mas essa é uma atitude questionada por alguns. A razão desse questionamento é que existem áreas na África onde a produção de alimentos, para o consumo humano, não é suficiente e usar parte dessa limitada produção voltada para fabricação de combustíveis é algo fora de cogitação (COYLE, 2012; GAROFALO, 2005).

\subsubsection{FATORES ECONÔMICOS}

A África possui um grande poderio de ações para investimentos econômicos em biocombustíveis. Mas apesar de existir os recursos necessários para serem investidos nessa área, eles não são usados. Como atualmente a África não possui um plano ou programa definido de desenvolvimento de biocombustíveis, profissionais qualificados, tecnologia de ponta e crescimento industrial migram para outras regiões. Em 2013, a África do Sul firmou um acordo com o Brasil visando o aumento de produção de biocombustíveis 
no país. Este acordo gerou reuniões entre representantes dos dois países e a expectativa é que a produção conjunta comece nos próximos anos (BAMBO, 2014; SIMBALOTI, 2011; WI, 2008).

\subsection{EUROPA}

\subsubsection{Fatores Políticos}

Em 2008, foi criada na União Europeia (UE), a RED/FQD (Renewable Energy Directive and Fuel Quality Directive). Esta medida foi sugerida para dezenas de países da Europa e trata-se de uma proposta ousada. Uso máximo de $60 \%$ de automóveis movidos a combustíveis fósseis, mínimo de $5 \%$ da frota de automóveis movidos $100 \%$ a biocombustíveis, além de um plano de investimento bilionário até 2020 (CHACON, 2004; KORBITZ; BERGER, 2004; TANAKA, 2011).

Em sua diretiva de Biocombustíveis, a União Europeia estabeleceu também a meta de que em 2010, cada Estado membro deveria atingir, no mínimo, 5,75\% de uso de biocombustíveis em comparação com todos os combustíveis utilizados. Em 2020 o número deve ser de 10\% (CHACON, 2004; KORBITZ; BERGER, 2004; TANAKA, 2011).

A França começou em 2006, uma forte política fiscal de apoio a energias renováveis e em 2014, $40 \%$ do valor investido em combustíveis e energia, foi destinado a energias renováveis (CHACON, 2004; KORBITZ; BERGER, 2004; TANAKA, 2011).

Além de ser a maior produtora de biodiesel da Europa, a Alemanha aprovou legislação para promover o uso de biocombustíveis nos transportes até 2014, em parcial conformidade com a RED/FQD (KORBITZ; BERGER, 2004; CHACON, 2004).

A Espanha também promulgou a legislação para promover o uso de biocombustíveis nos transportes até 2013, também em parcial conformidade com a
RED /FQD (CHACON, 2004; KORBITZ; BERGER, 2004; TANAKA, 2011).

No Reino Unido, a partir de 2005, foi revogada a lei que toda a frota de automóveis deveria conter obrigatoriamente, no mínimo $5 \%$ de combustíveis renováveis em sua composição (CHACON, 2004; KORBITZ; BERGER, 2004; TANAKA, 2011).

\subsubsection{Fatores Ambientais e Geográficos}

Em 2008, um relatório feito pela instituição inglesa Royal Society, afirmava que se políticas incentivadoras dos biocombustíveis não fossem tomadas, grande parte dos problemas ambientais, como o Efeito Estufa e o Aquecimento Global continuariam crescendo exponencialmente. Em 2013, um relatório feito pela União Europeia mostrou que, além das ações tomadas em prol dos biocombustíveis estarem diminuindo a emissão de gases que contribuem para esse problema, a meta para 2020, é que essa emissão seja considerada mínima, comparada com números dos anos de 1990. Sendo essa a década onde os níveis de emissão de gases poluentes foram os mais elevados de acordo com o monitoramento desses fatores por institutos especializados (SMITH, 2012; SMITH, 2013).

\subsubsection{FATORES ECONÔMICOS}

A União Europeia (EU) tem um grande programa de investimento em desenvolvimento e pesquisa na produção de biocombustíveis. Diversos países têm grande potencial, tornando-se alguns anos, líderes na produção e consumo de biocombustíveis (SMITH, 2012; SMITH, 2013).

Através da FIG. 3 é possível notar quais são os maiores produtores de biocombustíveis na Europa. (SMITH, 2012; SMITH, 2013). 


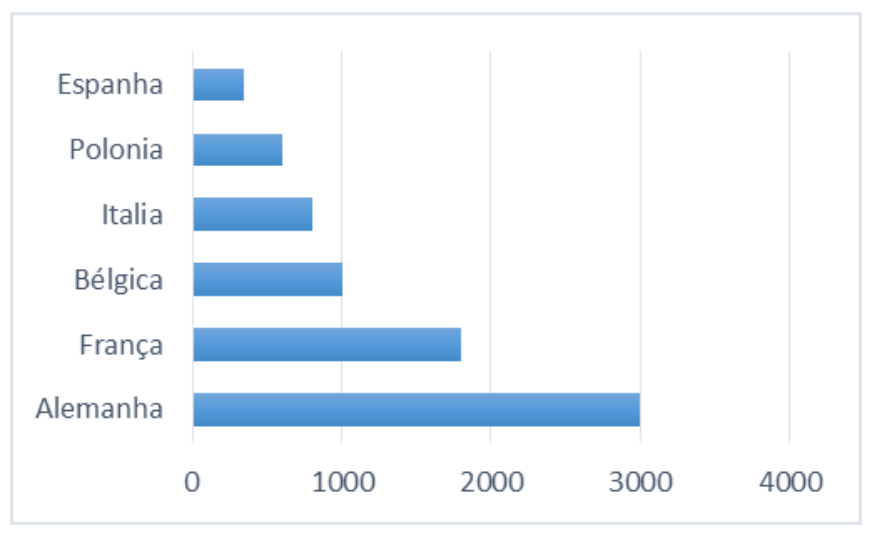

Figura 3 - Maiores produtores de biocombustíveis na Europa em 2014 (milhões de litros). Fonte: FLACH, 2014.

A França foi o segundo maior consumidor de biocombustíveis entre os membros da UE em 2006. De acordo com o Ministério da Indústria francês, o consumo aumentou $62,7 \%$, atingindo $1,6 \%$ do consumo de combustível do país. Sendo que o biodiesel representa a maior parcela deste $(78 \%)$, muito à frente de bioetanol com $22 \%$. Atualmente, a França é o líder europeu no consumo de biocombustíveis (SMITH, 2012; SMITH, 2013).

A Alemanha foi 0 maior consumidor de biocombustíveis da Europa em 2006, com uma estimativa de consumo de 2,8 milhões de toneladas de biodiesel, 0,71 milhões de toneladas de óleo vegetal e 0,48 milhões de toneladas de bioetanol (SMITH, 2012; SMITH, 2013).

\section{5 ÁsıA}

\subsubsection{Fatores Políticos}

A China apresenta uma população gigantesca que cotidianamente consome altíssimas quantidades combustíveis. Uma medida favorável aos biocombustíveis, tomada pelo governo chinês foi o de estipular o E10 (10\% de álcool na gasolina) obrigatório em cinco províncias chinesas, que respondem por 16\% dos veículos da frota do país (GOTO, 2010; ZHOU, 2009).
Na Índia, um programa de bioetanol E5 foi estipulado a partir de 2007. A ideia era continuar desenvolvendo o biocombustível no país e em seguida, aumentar a composição de combustíveis para E10 e E20 (GOTO, 2010; ZHOU, 2009).

As Filipinas também estipularam uma mistura de 10\% de etanol na gasolina desde 2007. Por razões semelhantes, a indústria do óleo de palma planeja fornecer uma parcela crescente de participação nas exigências nacionais de biodiesel na Malásia e Indonésia (GOTO, 2010; ZHOU, 2009).

Israel teve como objetivo de até 2012, possuir de 4$5 \%$ do mercado de biocombustíveis global. Apesar de não ter alcançado este objetivo, atualmente o país é referência no uso de biocombustíveis no Oriente Médio. O governo está focado exclusivamente em matérias-primas fora do escopo do consumo humano, ou seja, em biocombustíveis de segunda geração, de fontes como: pinhão manso, mamona, biomassa celulósica e algas (GOTO, 2010; ZHOU, 2009).

Já o governo do Paquistão espera construir nos próximos anos, biodigestores para a produção de biogás em áreas rurais, para complementar os rendimentos de gás, promovendo com isso o consumo de fontes renováveis no país (GOTO, 2010; ZHOU, 2009).

\subsubsection{Fatores Ambientais e Geográficos}

Em termos de potencial de plantio, a Ásia, assim como a América do Sul e África, apresenta um enorme potencial (KOIZUMI, 2005; USAIDB, 2008).

Cientes disso, nesses últimos anos, países como a Índia e China aumentaram muito sua produção de matérias primas voltadas aos biocombustíveis. Com uma política favorável, excesso de mão de obra e terra fértil disponível para plantio, a Ásia tem grande potencial, para assim como a América do Sul, estar entre os maiores produtores, de diferentes fontes, 
para a produção de biocombustíveis. Entretanto, a fórmula asiática para o avanço é distinta da América do Sul, pois pretende também, se tornar uma potência em tecnologias de produção. Essa fórmula deixaria países como a China, no controle de grande uma grande parcela mundial desse setor (KOIZUMI, 2005; USAIDB, 2008).

\subsubsection{FATORES ECONÔMICOS}

A Ásia não dispõe de vastos recursos financeiros para serem investidos em pesquisa e desenvolvimento para a produção de biocombustíveis se comparada com países da América do Norte e Europa. Apesar de limitado, o investimento existe e já traz resultados para alguns países. A extensa produção de matéria prima e a mão de obra barata fazem com que outros governos invistam, nesse setor, na Ásia (KOIZUMI, 2005; USAIDB, 2008).

No presente esse investimento está sendo usado de forma sábia por alguns países da região, que investem em tecnologia e pesquisa direcionadas ao aumento da produção, o que traz mais investimentos dos países estrangeiros, criando assim um ciclo, totalmente favorável aos países asiáticos (KOIZUMI, 2005; USAIDB, 2008).

\section{Conclusão}

No momento os biocombustíveis são o potencial substituto mundial dos combustíveis fósseis. $\mathrm{O}$ primeiro fator que leva a essa conclusão é o fato imutável de que o petróleo irá se exaurir um dia. Além disso, fatores como o custo-benefício, praticidade de produção e desenvolvimento tecnologias relativas a outras fontes energéticas, podem acelerar ainda mais essa substituição.

O mundo já está ciente desta transição. Alguns países já investem forte para realizar essa mudança o mais rápido possível. Outros ainda estão ligados fortemente a políticas pró-petróleo e não alteraram significativamente seu status quanto ao desenvolvimento de fontes energéticas alternativas.

Europa e América do Norte investem intensivamente visando atingir, brevemente, o controle do mercado de biocombustíveis. A Ásia também apresenta metas e ações para conseguir uma fatia desse mercado mundial. A América do Sul possui hoje uma produção vasta de biocombustíveis, mas não dispõe dos recursos e investimentos adequados para desfrutar dessa sua vantagem. Já a África, apesar de seu enorme potencial, necessita de uma mudança de postura para participar efetivamente do mercado mundial de biocombustíveis.

A conjuntura atual demonstra que em alguns anos grandes transformações ocorrerão no cenário energético mundial. Além de mudanças nos paradigmas de certos países, os quais tratavam os combustíveis fósseis como infindáveis. Os altos investimentos disponibilizados nas áreas de pesquisa e desenvolvimento tendem a minimizar problemas como a eficiência energética, aumentando a viabilidade dos biocombustíveis de primeira e segunda geração.

\section{REFERÊNCIAS}

APEX; Estados Unidos Perfil E Oportunidades Comerciais Para Alimentos, Bebidas E Agronegócios, Apex Brasil, 2014
BAMBO T. F.; Cooperação Sul-Sul: O Acordo BrasilMoçambique Na Area De Biocombustíveis. São Paulo, 2014 
CARRIQUIRY M; DU X.; TIMILSINA G. R.; SecondGeneration Biofuels - Economics and Policies. The World Bank. August 2010.

CHACON F. A. T.; Techno-Economic Assessment of Biofuel Production in Europian Union. Fraunhofer Institute for Systems and Innovation Research. Karlsruhe, 2004.

COYLE W.; Global Biofuel Production and Food Security: Implications for Asia Pacific. 56th AARES Annual Conference. Australia, February, 2012.

DIOP D.; BLANCO M. Assessing the impact of biofuels production on developing countries from the point of view of Policy Coherence for Development. European Commisson - February, 2013

DUFEY A.; GRIEG M.; Biofuels production, trade and sustainable development. IIED - International Institute for Environmental and Development. London, 2010.

ECONOMIST; Biofuels and its details. The Economist The Wall Street Journal. 2011

FLACH B et all; Biofuels Annual 2014. Global Agriculture Informatuion Network. The Hague 2014.

GADONNEIX P.; Biofuels: Policies, Standards and Technologies. World Energy Council, 2010.

GAROFALO R.; Biodiesel Chains: Promoting Favourable Conditions to Establish Biodiesel Market Actions. Biodiesel Report Chains. Brussels. 2005.

GAROFALO R.; State of Play of European Biodiesel. EEB - European Biodiesel Board. January, 2013.

GOTO S.; Current Status of Biodiesel Fuel in EastAsia and ASEAN countries. Benchmarking of Biodiesel Fuel Standardization in East Asia Working Group. July 2010.

KOIZUMI T.; Biofuel Programs in East Asia:

Developments, Perspectives, and Sustainability. Policy Research Institute, Ministry of Agriculture, Forestry and Fishery. Japan, 2005.

KORBITZ W.; BERGER C.; Best Case Studies on Biodiesel Production Plants in Europe. Austrian Biofuels Institute - 2004.

LUCON O.; Sustainability of Biofuels Production in Latin America. BioTop - Biofuels RTD - cooperation, 2008.
MARTIN S. et al; An experimental investigation of biodiesel steam reforming. Science Direct, November 2014.

MAURON M. R.; A Produção Integrada De Etanol E Alimentos Por Camponeses Como Uma Oportunidade Para O Desenvolvimento Rural Sustentável Do Rio Grande Do Sul. Rio de Janeiro, 2014

NOLTE G. E.; Peru Biofuels Annual. Peru, 2012. Portal do Professor. Ministério da Educação, 2012. Disponível em < http://portaldoprofessor.mec.gov.br/fichaTecnicaAula.h tml?aula=41373 >. Acesso em: 08 ago. 2013

SCHOTT C. Socio-economic Dynamics of Biofuel Development in Asia Pacific. Friedrich Ebert Stiftung, Jakarta, 2009.

SIMBALOTI G.; Production of Liquid Biofuels. Technology Brief. International Renewable Energy Agency. 2011.

SIMS R.; TAYLOR M.; From first to second generation biofuel technologies. IEA Bioenergy, OEC/IEA November, 2008.

SMITH M. E.; Annual Biofuels Report - 2012. Agricultural Institute of The Netherlands. The Hague, 2012.

SMITH M. E.; Annual Biofuels Report - 2013. Agricultural Institute of The Netherlands. The Hague, 2013.

SOARES I. P. et al; Biodiesel: desafios e oportunidades. Comunicado Técnico. Brasília, 2014. Statistical Review of World Energy. BP International. June 2013.

TANAKA N; Technology Roadmap. Biofuels for Transportation. International Energy Agency. 2011.

TAVORA F. L., Biodiesel e proposta de um novo Marco Regulatório: Obstáculos e Desafios, pág. 12, 2012.

UNITED STATES AGENCY FOR INTERNATIONAL DEVELOPMENT (USAIDB); Biofuels in Asia - An Analysis of Sustainability Options. United States Agency for International Development. Bangkok, 2008.

WI C. et al; Process Development for scum to biodiesel conversion. University of Beijing, May 2015. 
ZHOU A.; THOMSON E.; The Development of

Biofuels in Asia. Energy Studies Institute, National University of Singapure. April 2009. 